\title{
Intestinal glutamine and ammonia metabolism during chronic hyperammonaemia induced by liver insufficiency
}

\author{
Cornelis H C Dejong, Nicolaas E P Deutz, Peter B Soeters
}

\begin{abstract}
During liver insufficiency, besides portasystemic shunting, high arterial glutamine concentrations could enhance intestinal glutamine consumption and ammonia generation, thereby aggravating hyperammonaemia. To investigate this hypothesis, portal drained viscera (intestines) fluxes and jejunal tissue concentrations of ammonia and glutamine were measured in portacaval shunted rats with a ligated bile duct, portacaval shunted, and sham operated rats, seven and 14 days after surgery, and in normal unoperated controls. Effects of differences in food intake were minimised by pair feeding portacaval shunted and sham operated with portacaval shunted rats with biliary obstruction. At both time points, arterial ammonia was increased in the groups with liver insufficiency. Also, arterial glutamine concentration was raised in all operated groups compared with normal unoperated controls. At both time points, ammonia production by portal drained viscera was reduced in portacaval shunted rats with biliary obstruction, portacaval shunted, and sham operated rats compared with normal unoperated controls, and no major differences were found between these operated groups. At day 7 in all operated groups glutamine uptake by portal drained viscera was lower than in normal unoperated controls, but no major differences were found at day 14. These experiments show that ammonia generation by portal drained viscera remains unchanged in rats with chronic liver insufficiency despite alterations in arterial glutamine concentrations and intestinal glutamine uptake. The hyperammonaemia seems to be mainly determined by the portasystemic shunting.

(Gut 1993; 34: 1112-1119)
\end{abstract}

Ammonia is still considered to be of crucial importance in the pathogenesis of hepatic encephalopathy. ${ }^{1}$ The gut and kidney are generally considered to be the most important sites of ammonia production. ${ }^{2-5}$ In the gut, the main sources of ammonia production are the bacterial breakdown of urea ${ }^{2367}$ and the mucosal utilisation of glutamine as an energy substrate. ${ }^{2378}$ In the physiological situation virtually all ammonia generated in the gut is immediately cleared by hepatic urea synthesis, and thus hepatic venous ammonia concentrations are lower than arterial concentrations. Therefore, in healthy subjects, systemic ammonia concentrations are probably mainly set by the interaction between renal ammonia production and ammonia consumption by other organs. During liver cirrhosis induced by chronic liver disease this situation changes drastically, because ammonia generated in the intestines bypasses hepatic clearance by intra or extrahepatic portasystemic shunts. ${ }^{910}$ Also, the diminished urea synthesis and glutamine synthetase capacity ${ }^{11}$ may reduce ammonia detoxification in the liver. These combined factors probably cause the systemic hyperammonaemia found during liver insufficiency.

It has been suggested that systemic hyperammonaemia during chronic liver failure leads to enhanced ammonia detoxification via alternative pathways. ${ }^{12}$ It is generally believed that the energy dependent synthesis of glutamine from equimolar amounts of glutamate and ammonia is the most important of these pathways. ${ }^{13}$ This glutamine synthesis in organs containing glutamine synthetase, mainly skeletal muscle and brain, ${ }^{14}$ probably contributes to the raised arterial glutamine concentrations during hyperammonaemia induced by liver insufficiency. ${ }^{12}$ Because intestinal glutamine uptake is concentration dependent, ${ }^{7}$ these increased arterial glutamine concentrations in turn could increase intestinal glutamine utilisation and subsequent liberation of ammonia.

A considerable amount of research has been performed concerning several aspects of ammonia and glutamine metabolism during acute and chronic liver insufficiency (see for example, ${ }^{46^{12} 15^{18}}$ and also our laboratory ${ }^{120}$ ). Despite the well known effects of food intake on nitrogen metabolism in general and more specifically on glutamine and ammonia metabolism, ${ }^{21}$ few studies have been performed under conditions of controlled food intake during hyperammonaemia induced by liver insufficiency.

The hypothesis underlying the present study was that during chronic liver insufficiency, besides portasystemic shunting, high arterial glutamine concentrations could aggravate hyperammonaemia by enhanced intestinal glutamine consumption and ammonia generation. To test this hypothesis the exhange of ammonia, glutamine, and several other amino acids across the portal drained viscera (gut) as well as jejunal tissue concentrations were measured in two models of hyperammonaemia induced by chronic liver insufficency in rats: portacaval shunting and portacaval shunting combined with bile duct ligation, as well as in appropriate controls. Portacaval shunting combined with biliary tract ligation was recently suggested to be a reliable, new model for hyperammonaemia induced by chronic liver insufficiency and to induce a more pronounced 
clinical degree of hepatic encephalopathy than portacaval shunting alone. ${ }^{22}$ To minimise effects of differences in food intake, the portacaval shunted and the sham operated groups were pair fed with the anorectic portacaval shunt and biliary obstruction group.

\section{Materials and methods}

\section{ANIMALS}

Male Wistar rats ( $\mathrm{n}=56$, weight 300 (SEM 25)g) were used throughout. They were housed under standard conditions (12/12 hour light/dark cycle) and received standard food and water ad libitum until surgery. Rats were maintained and humanely cared for according to the recommendations of the guide for the care and use of laboratory animals as applied in our institute.

\section{GROUPS}

Four groups were studied: (1) PCSBDL group, portacaval shunting (PCS) combined with bile duct ligation (BDL) in one surgical session; (2) PCS-PF group, Portacaval shunting; (3) PF group, laparotomy and manipulations as in PCSPF rats, but without shunting (sham operation); (4) normal group, sampling without previous surgery; normal unoperated control rats receiving food ad libitum.

Before surgery, the rats were randomly assigned to one of the groups. Surgical procedures were of equal duration in PCS-PF and $\mathrm{PF}$ rats and their individual PCSBDL mate. After resuscitation from surgery, PCSBDL,
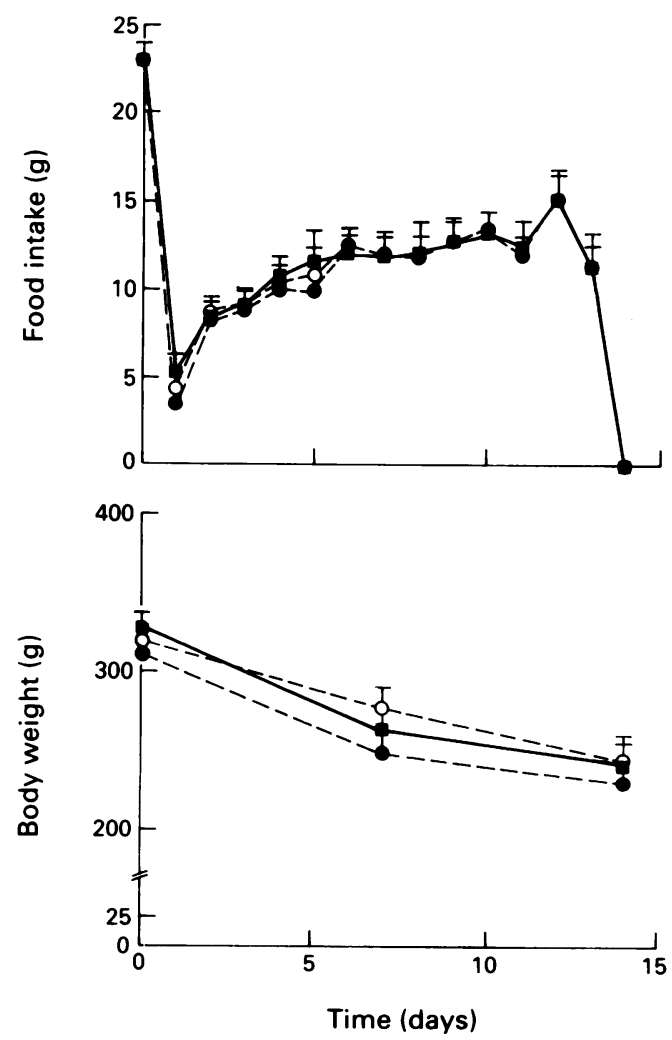

Figure 1: Food intake (upper panel) and body weight (lower panel) in PCSBDL ( $), P C S-P F(O)$ and PF (O) rats during 14 days of pair feeding. Curves are means (SEM). $n=14$ to 16 in the first seven days and six to eight rats between days 7 and 14 .
PCS-PF, and PF rats were placed in metabolic cages. The PCSBDL rats had free access to standard pellet food. In these rats, daily food intake was recorded and this amount was administered to fixed PCS-PF and PF mates to minimise effects of differences of food intake (pair feeding: PF). In the PCSBDL, PCS-PF, and PF groups blood was sampled seven or 14 days after surgery (see later). Body weight was measured at the intervals indicated in Fig 1. All groups were allowed ad libitum water.

\section{BEHAVIOUR}

Before they were used in experiments and before sampling, the behaviour of all rats was studied during a 5 minute period to estimate the degree of hepatic encephalopathy. Specific attention was paid to appearance, presence of lethargy, spontaneous locomotor activity and exploratory behaviour, presence of tiptoe gait, toeing out, and arched back, reaction to tail pinching, and presence of ataxia. Because the PCSBDL rats were jaundiced, this staging procedure could not be performed blinded.

\section{SURGERY}

Surgery and sampling were performed under ether anaesthesia. Portacaval shunting was by the button technique. ${ }^{19}{ }^{23}$ Biliary obstruction was achieved by ligating the common bile duct near the liver and near the duodenum and removing the piece between the ligatures. In PCS-PF and PF rats the bile duct was manipulated but not dissected, to avoid stenosis.

\section{SAMPLING}

Before sampling, rats were fasted overnight. Sampling procedures were performed as described elsewhere. ${ }^{192124}$ Briefly, rats were anaesthetised 30 minutes before sampling and the portal vein and a tertiary branch of the superior mesenteric vein were cannulated with needle bearing microcatheters fixed in place with cyanoacrylate adhesive. The right common carotid artery was catheterised with polyethylene tubing (PE 50). For flow determinations, after a priming dose, a $5 \mathrm{mM}$ iso-osmolar $\mathrm{pH}$ adjusted $p$-aminohippuric acid (PAH) solution was continuously infused into the mesenteric vein

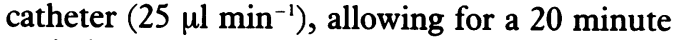
period to attain steady state concentrations. ${ }^{2025}$ Blood was slowly and simultaneously aspirated from the portal vein and carotid artery and put in heparinised tubes on ice. Finally, about $10 \mathrm{~cm}$ distal to Treitz's ligament, a $10 \mathrm{~cm}$ piece of jejunum was excised and frozen in liquid nitrogen..$^{24}$ Rats were killed by an overdose of the anaesthetic. These procedures permit simultaneous determination of blood flow and arteriovenous concentration difference (flux) across the portal drained viscera (intestines), ${ }^{1921}{ }^{24}$ as well as the tissue concentration measurements.

\section{ANALYSIS}

Blood samples were kept on ice during processing. Plasma for determination of amino acids, ammonia, and urea was obtained by 
TABLE I Behaviour

\begin{tabular}{|c|c|c|c|c|c|c|c|}
\hline & \multirow{2}{*}{$\begin{array}{l}\text { Day0 } \\
\text { Normal }\end{array}$} & \multicolumn{3}{|c|}{ Day 7} & \multicolumn{3}{|c|}{ Day 14} \\
\hline & & $P F$ & $P C S-P F$ & $P C S B D L$ & $P F$ & $P C S-P F$ & $P C S B D L$ \\
\hline "Gerbil" appearance & $0 / 10$ & $4 / 8$ & $5 / 8$ & $8 / 8$ & $1 / 8$ & $5 / 8$ & $6 / 6$ ' \\
\hline Toeing out (hindlimbs) & $0 / 10$ & $0 / 8$ & $0 / 8$ & $6 / 8$ w & $0 / 8$ & $6 / 8$ & $6 / 6$. \\
\hline Tiptoe gait & $0 / 10$ & $0 / 8$ & $1 / 8$ & $3 / 8$ & $0 / 8$ & $1 / 8$ & $6 / 6$ su \\
\hline "Duck" gait & $0 / 10$ & $0 / 8$ & $1 / 8$ & $3 / 8$ & $0 / 8$ & $2 / 8$ & $6 / 6$ su \\
\hline Arched back & $0 / 10$ & $0 / 8$ & $1 / 8$ & $3 / 8$ & $0 / 8$ & $3 / 8$ & $5 / 6$ \\
\hline Ataxia & $0 / 10$ & $0 / 8$ & $0 / 8$ & $2 / 8$ & $2 / 8$ & $6 / 8$ & $6 / 6^{\prime}$ \\
\hline
\end{tabular}

All items were scored on a dichotomic basis (present or absent). Data are rats with item/total. Fischer's one tailed exact test: $v$ PF ${ }^{a} p<0.05 ;{ }^{\prime} p<0.01 ;{ }^{p} p<0.001$. $v$ PCS-PF $\mathrm{p}<<0.05$, ${ }^{\mathrm{p}} \mathrm{p}<0.01$, ${ }^{\mathrm{v}} \mathrm{p}<0.001$.

centrifugation of whole blood at $4^{\circ} \mathrm{C}$ for five minutes at $8800 \mathrm{~g}$. Packed cell volume was obtained with a microfuge. Plasma and tissue were stored at $-70^{\circ} \mathrm{C}$. For tissue ammonia and amino acid determinations, $5 \%(\mathrm{w} / \mathrm{v})$ sulphosalicylic acid extracts were prepared. ${ }^{19}$ Tissue water content was determined as described previously.$^{20}$ Ammonia, urea, lactate and glucose were determined enzymatically, ${ }^{19}$ and amino acids by high performance liquid chromatography. ${ }^{26}$ P-Aminohippuric acid (PAH) was determined as described previously. ${ }^{19}$ Total bilirubin was measured in plasma with commercial kits (Roche, Basel, Switzerland). The coefficient of variance for all determinations was below $4 \% .1926$

CALCULATIONS

Plasma PAH concentration was calculated from whole blood PAH concentrations with the packed cell volume. Plasma flow was calculated from the formula $F_{P D V}=I /\left([P A H]_{P}-[P A H]_{A}\right)$ where $F_{P D V}$ is the portal drained viscera plasma flow $\left(\mathrm{ml} \cdot \mathrm{min}^{-1}\right), \mathrm{I}$ is the infused PAH ( $\mu$ mole. $\mathrm{min}^{-1}$ ), and $[\mathrm{PAH}]_{\mathrm{P}}$ and $[\mathrm{PAH}]_{\mathrm{A}}$ are the plasma $\mathrm{PAH}$ concentrations $(\mu M)$ in the portal vein and carotid artery respectively. Portal drained viscera fluxe (nmole.100 $\mathrm{g}$ body weight ${ }^{-1} \cdot \mathrm{min}^{-1}$ ) was calculated as plasma flow $\times$ portal venous-arterial concentration difference. Positive figures mean net efflux, negative values net uptake. Fractional glutamine extraction was calculated as the arterial-portal vein concentration difference divided by the arterial concentration ((A-PV)/ A) $100 \%)$. Urea values were corrected for ammonia. $\alpha$ Amino nitrogen $(\alpha \mathrm{AN})$ was calculated as the sum of the individual amino acids measured. ${ }^{26}$

\section{STATISTICS}

Calculations were with the SPSS/PC+ statistical software package, version 3.1 (SPSS Inc, Chicago, IL, USA). Data are presented as means $(\mathrm{SEM})$, $\mathrm{p}$ values $<0.05$ were considered significant. The tests used were: analysis of variance for group effects (ANOVA) and time effects within groups (ONEWAY); the non-parametric MannWhitney $U$ test for differences between groups at specific time points; Wilcoxon's non-parametric test for differences from zero; and Fischer's exact test for differences in encephalopathy

TABLE II Arterial concentrations

\begin{tabular}{|c|c|c|c|c|c|c|c|}
\hline & \multirow{2}{*}{$\begin{array}{l}\text { Day0 } \\
\text { Normal }\end{array}$} & \multicolumn{3}{|l|}{ Day 7} & \multicolumn{3}{|l|}{ Day 14} \\
\hline & & $P F$ & $P C S-P F$ & PCSBDL & $P F$ & $P C S-P F$ & $P C S B D L$ \\
\hline $\begin{array}{l}\text { Bilirubin } \\
\text { Glucose } \\
\text { Lactate } \\
\text { Ammonia } \\
\text { Urea } \\
\text { Glutamate } \\
\text { Glutamine } \\
\text { Glycine } \\
\text { Citrulline } \\
\text { Alanine } \\
\text { Taurine } \\
\text { BCAA } \\
\text { AAA } \\
\alpha \text { Amino nitrogen }\end{array}$ & $\begin{array}{c}1 \cdot 3(0 \cdot 1) \\
7 \cdot 9(0 \cdot 3) \\
3 \cdot 4(0 \cdot 3) \\
59(6) \\
7 \cdot 7(0 \cdot 4) \\
82(8) \\
554(12) \\
285(13) \\
43(2) \\
301(13) \\
153(9) \\
404(17) \\
138(7) \\
3016(84)\end{array}$ & $\begin{array}{c}1 \cdot 2(0 \cdot 1) \\
9 \cdot 4(0 \cdot 7) \\
4 \cdot 5(1 \cdot 0) \\
59(12) \\
7 \cdot 1(0 \cdot 4) \\
70(7) \\
592(20) \mathrm{m} \\
270(16) \\
41(2) \\
264(21) \\
169(9) \\
394(26) \\
125(9) \\
2831(91)\end{array}$ & $\begin{array}{c}2 \cdot 4(0 \cdot 4) \mathrm{b} \\
8 \cdot 9(0 \cdot 5) \\
9 \cdot 0(0 \cdot 7) \mathrm{B} \\
199(19) \mathrm{bn} \\
6 \cdot 1(0 \cdot 4) \\
79(14) \\
644(23) \mathrm{a} \\
265(19) \\
45(5) \\
393(46) \mathrm{g} \\
266(29) \mathrm{g} \\
337(37) \\
167(10) \mathrm{B} \\
3201(170)\end{array}$ & $\begin{array}{c}119 \cdot 9(7 \cdot 6) \\
7 \cdot 1(0 \cdot 2){ }^{\mathrm{ik}} \\
10 \cdot 5(0 \cdot 8) \\
196(20) \\
6 \cdot 1(0 \cdot 2){ }^{8} \\
55(5)^{8} \\
713(40)^{\mathrm{ko}} \\
278(23) \\
55(3) \\
409(39) \\
510(24) \\
318(27) \\
221(10) \\
3593(156)\end{array}$ & $\begin{array}{c}1 \cdot 3(0 \cdot 1) \\
9 \cdot 4(0 \cdot 4) \\
5 \cdot 3(0 \cdot 7) \\
68(7) \\
7 \cdot 7(0 \cdot 2) \\
61(7) \\
604(24) \mathrm{m} \\
276(15) \\
42(1) \\
263(25) \\
203(11) \\
394(18) \\
131(7) \\
2835(95)\end{array}$ & $\begin{array}{l}2 \cdot 6(0 \cdot 3) \text { ch } \\
8 \cdot 0(0 \cdot 4) \\
9 \cdot 2(0 \cdot 9) \text { ch } \\
181(26) \text { cho } \\
6 \cdot 4(0 \cdot 3) \\
66(7) \\
609(17) \text { " } \\
252(10) \\
47(2) \\
385(19) \\
215(16) \\
354(20) \\
173(8) \text { ch } \\
3069(104)\end{array}$ & 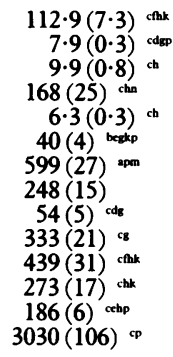 \\
\hline
\end{tabular}

Data are expressed as means (SEM) in $\mu M$, except urea, glucose, and lactate (LAC) which are expressed in mM. BCAA =branchedchain amino acids (leucine, isoleucine, and valire); $\mathrm{AAA}=$ aromatic amino acids (tyrosine and phenylalanine). ANOVA for group effects; $\mathrm{t}=7$ to $\mathrm{t}=14$ days: $v \mathrm{PF}{ }^{\mathrm{c}} \mathrm{p}<0.05,{ }^{\mathrm{b}} \mathrm{p}<0.01,{ }^{\mathrm{c}} \mathrm{p}<0.001$; $v$ PCS-PF ${ }^{\mathrm{d}} \mathrm{p}<0.05,{ }^{\mathrm{c}} \mathrm{p}<0.01,{ }^{\mathrm{p}} \mathrm{p}<0.001$. Mann-Whitney $U$ test for differences between groups: $v$ PF ${ }^{\mathrm{s}} \mathrm{p}<0.05,{ }^{\mathrm{b}} \mathrm{p}<0.01,{ }^{\mathrm{p}} \mathrm{p}<0.001 ; v \mathrm{PCS}-\mathrm{PF}{ }^{\mathrm{p}} \mathrm{p}<0.05,{ }^{\mathrm{k}} \mathrm{p}<0.01,{ }^{\prime} \mathrm{p}<0.001 ; v$ normal ${ }^{\mathrm{m}} \mathrm{p}<0.05,{ }^{\mathrm{n}} \mathrm{p}<0.01,{ }^{\mathrm{p}} \mathrm{p}<0.001$.

Wilcoxon test; $\neq$ not significantly different from zero. ONEWAY procedure for time effects with groups ${ }^{\mathrm{p} p}<0 \cdot 05$.

TABLE III Metabolite fluxes and plasma flows in portal drained viscera

\begin{tabular}{|c|c|c|c|c|c|c|c|}
\hline & \multirow{2}{*}{$\begin{array}{l}\text { Day 0 } \\
\text { Normal }\end{array}$} & \multicolumn{3}{|l|}{ Day 7} & \multicolumn{3}{|l|}{ Day 14} \\
\hline & & $P F$ & $P C S-P F$ & PCSBDL & $P F$ & $P C S-P F$ & $P C S B D L$ \\
\hline $\begin{array}{l}\text { Flow } \\
\text { Ammonia } \\
\text { Glutamate } \\
\text { Glutamine } \\
\text { Glycine } \\
\text { Citrulline } \\
\text { Alanine } \\
\text { Taurine } \\
\text { BCAA } \\
\text { AAA } \\
\alpha \text { Amino nitrogen } \\
\text { FE }_{\text {GLN }}\end{array}$ & $\begin{array}{c}3 \cdot 1(0 \cdot 9) \\
413(62) \\
20(14)^{\ddagger} \\
-486(49) \\
47(19) \\
51(9) \\
169(57) \\
30(15)^{\ddagger} \\
-26(31)^{\ddagger} \\
-11(15)^{\ddagger} \\
-315(180)^{\ddagger} \\
28 \cdot 1(2 \cdot 5)\end{array}$ & $\begin{array}{c}0 \cdot 8(0 \cdot 2) " \\
99(33)^{\circ} \\
5(1) \\
127(12)^{\circ} \\
19(8) \\
10(2)^{\circ} \\
74(20) \\
11(9)^{\ddagger} \\
14(9)^{\ddagger} \\
2(3)^{\ddagger} \\
16(46)^{\ddagger} \\
27 \cdot 9(2 \cdot 5)\end{array}$ & $\begin{array}{c}2 \cdot 3(1 \cdot 4) \\
221(47){ }^{\mathrm{sm}} \\
-1(15) \\
-351(48) \\
33(19) \\
45(14) \\
215(69) \\
9(30) \\
27(27)^{\ddagger} \\
5(9)^{\ddagger} \\
-24(174)^{\ddagger} \\
23 \cdot 7(3 \cdot 7)^{\mathrm{b}}\end{array}$ & 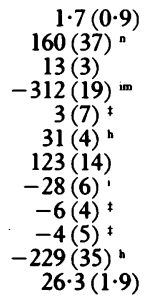 & $\begin{array}{c}2 \cdot 4(1 \cdot 2) \\
295(74)^{p} \\
40(9)^{r} \\
-566(53)^{p} \\
118(17)^{r} \\
67(10)^{r} \\
403(45)^{r} \\
83(31)^{r} \\
75(24)^{r} \\
19(6)^{r} \\
399(101)^{r} \\
39 \cdot 5(3 \cdot 1)^{m p}\end{array}$ & $\begin{array}{c}2 \cdot 7(1 \cdot 1) \\
328(81) \\
16(7)^{\ddagger} \\
-386(64) \\
57(12)^{*} \\
57(12) \\
256(57)^{*} \\
72(35) \\
44(23)^{*} \\
8(5)^{\ddagger} \\
186(126)^{*} \\
23 \cdot 6(3 \cdot 9)^{t h}\end{array}$ & 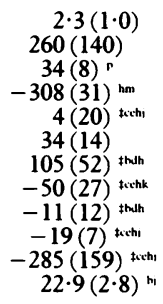 \\
\hline
\end{tabular}

Data are means $(\mathrm{SEM})$ in nmole. $100 \mathrm{~g}$ body $\mathrm{wt}^{-1} \cdot \mathrm{min}^{-1}$, except plasma flows, which are in $\mathrm{ml} .100 \mathrm{~g}$ body $\mathrm{wt}^{-1} \cdot \mathrm{min}^{-1} ; \mathrm{FE}_{\mathrm{GLN}}=\mathrm{fractiona}$ glutamine extraction; for other abbreviations and significance symbols, see table II. 
TABLE IV Fejunal concentrations and water content

\begin{tabular}{|c|c|c|c|c|c|c|c|}
\hline & \multirow{2}{*}{$\begin{array}{l}\text { Day0 } \\
\text { Normal }\end{array}$} & \multicolumn{3}{|l|}{ Day 7} & \multicolumn{3}{|l|}{ Day 14} \\
\hline & & $P F$ & $P C S-P F$ & $P C S B D L$ & $P F$ & $P C S-P F$ & $P C S B D L$ \\
\hline $\begin{array}{l}\% \mathrm{H}_{2} \mathrm{O} \\
\text { Ammonia } \\
\text { Aspartate } \\
\text { Glutamate } \\
\text { Glutamine } \\
\text { Glycine } \\
\text { Citrulline } \\
\text { Alanine } \\
\text { Taurine } \\
\text { BCAA } \\
\text { AAA } \\
\alpha \text { Amino nitrogen }\end{array}$ & $\begin{array}{c}76 \cdot 9(0 \cdot 6) \\
1436(83) \\
752(47) \\
2579(74) \\
693(46) \\
1112(46) \\
171(10) \\
1041(52) \\
14821(645) \\
510(24) \\
219(25) \\
23404(773)\end{array}$ & $\begin{array}{c}77 \cdot 5(0 \cdot 7) \\
1213(69) \\
950(50) \\
2628(75) \\
778(34) \\
1071(62) \\
177(6) \\
1022(75) \\
15666(745) \\
506(44) \\
198(21) \\
24311(663)\end{array}$ & $\begin{array}{c}77 \cdot 6(0 \cdot 6) \\
1688(146)^{b} \\
853(60) \\
2872(146) \\
827(16) \\
1171(164) \\
192(20) \\
1180(96) \\
17105(661) \\
542(58)^{\mathrm{s}} \\
300(38)^{\mathrm{B}} \\
26662(771)^{\mathrm{B}}\end{array}$ & $\begin{array}{c}76 \cdot 9(0 \cdot 4) \\
1681(153)^{\mathrm{s}} \\
862(42)^{\mathrm{m}} \\
2853(96)^{\mathrm{m}} \\
870(35)^{\mathrm{m}} \\
958(70) \\
199(11) \\
1171(76) \\
17641(518)^{\mathrm{g}} \\
348(25)^{\mathrm{bk}} \\
272(19)^{\mathrm{B}} \\
26551(480)^{\mathrm{g}}\end{array}$ & $\begin{array}{c}77 \cdot 3(0 \cdot 5) \\
1391(91) \\
865(38) \\
2683(61) \\
693(25)^{p} \\
1220(67) \\
190(9) \\
1268(93)^{p} \\
17142(469) \\
682(73)^{p} \\
262(27) \\
26657(614)^{p}\end{array}$ & $\begin{array}{c}78 \cdot 0(0 \cdot 9) \\
1541(83)^{b} \\
749(52){ }^{a 8} \\
2533(145) \\
740(48) \\
1035(45)^{a} \\
185(12) \\
1147(51) \\
16957(802) \\
534(78) \\
287(33) \\
25655(834)\end{array}$ & $\begin{array}{c}77 \cdot 1(0 \cdot 6) \\
1634(152)^{\mathrm{b}} \\
738(53)^{\mathrm{ag}} \\
2839(111)^{\mathrm{am}} \\
856(56)^{\mathrm{bem}} \\
919(40)^{\mathrm{bdh}} \\
215(14)^{\mathrm{a}} \\
1011(72)^{\mathrm{g}} \\
18292(339)^{\mathrm{b}} \\
314(9)^{\mathrm{cthk}} \\
234(14) \\
26777(519)^{\mathrm{a}}\end{array}$ \\
\hline
\end{tabular}

Data are expressed as mean (SEM) in $\mu$ mole.kg wet weight ${ }^{-1}$. For abbreviations and significance symbols, see table II.
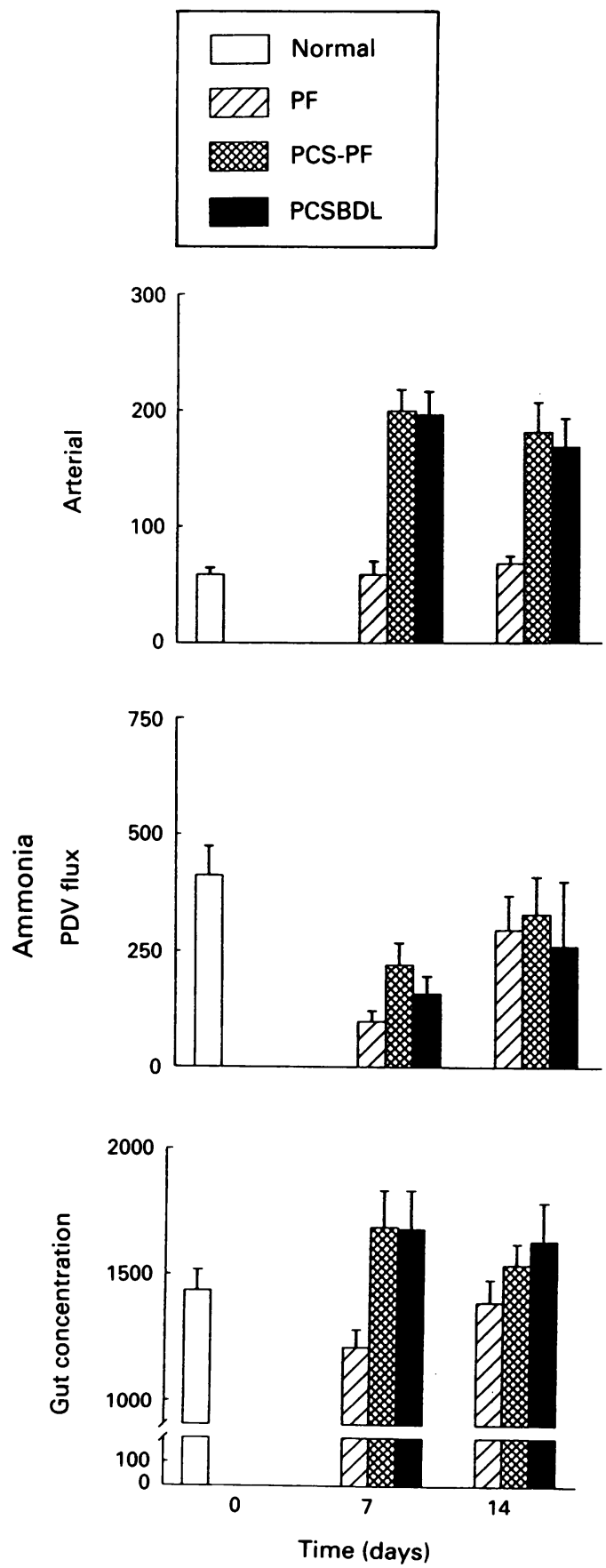

Figure 2: Ammonia: arterial concentrations (upper panel; $\mu M$ ), portal drained viscera fluxes (middle panel; nmole. 100 $\mathrm{g}$ body $w t^{\prime}$. min $^{-1}$ ), and jejunal tissue concentrations (lower panel; $\mu$ mole. $k g$ wet wt ${ }^{\prime}$ in normal control rats, sham operated pair fed rats $(P F)$, portacaval shunted rats (PCS$P F)$, and in rats with portacaval shunts and bile duct ligation $(P S C B D L)$. Data are means $(S E M) . n=6$ to 10 per group. stages (one tailed, binomial testing). Significances are indicated in Tables I-IV.

\section{Results}

GENERAL

Food intake and body weight (Fig 1) were similar in PCSBDL, PCS-PF, and PF rats. Specifically in PCSBDL rats, no signs of systemic or local inflammation or impaired wound healing were found. These rats seemed to be more encephalopathic as evidenced by abnormalities in gait, decreased spontaneous locomotor activity, and exploratory behaviour (Table 1). Total arterial bilirubin concentrations (Table II) were increased in PCS-PF compared with PF rats, as noted previously, ${ }^{27}$ and in PCSBDL rats compared with PCS-PF rats. In both hyperammonaemic groups, arterial glucose concentrations were decreased and lactate concentrations were raised in comparison with $\mathrm{PF}$ rats (Table II). Portal drained viscera plasma flow (Table III) was decreased in the PF group at day 7 when compared with normal unoperated control rats, but no further differences in portal plasma flow were found between the PCSBDL, PCS-PF, and PF groups.

\section{AMMONIA}

Arterial ammonia concentrations were raised equally in PCSBDL and PCS-PF rats on both day 7 and day 14. No major differences in ammonia production by portal drained viscera were found between PCSBDL, PCS-PF, and PF rats, and ammonia production by portal drained viscera in the hyperammonaemic groups never exceeded that in normal control rats. In fact, it was lower in all operated groups at day 7 compared with normal unoperated controls. Although no major changes occurred in ammonia release by portal drained viscera ammonia concentrations in jejunal tissue were raised in both hyperammonaemic groups (Fig 2; Tables II-IV).

\section{GLUTAMINE}

Arterial glutamine concentrations were always higher in PCSBDL, PCS-PF, and PF than in normal rats. Also, at day 7 arterial glutamine concentrations were raised in PCSBDL compared with PF rats, but no differences were found at day 14. At day 7, glutamine uptake by 


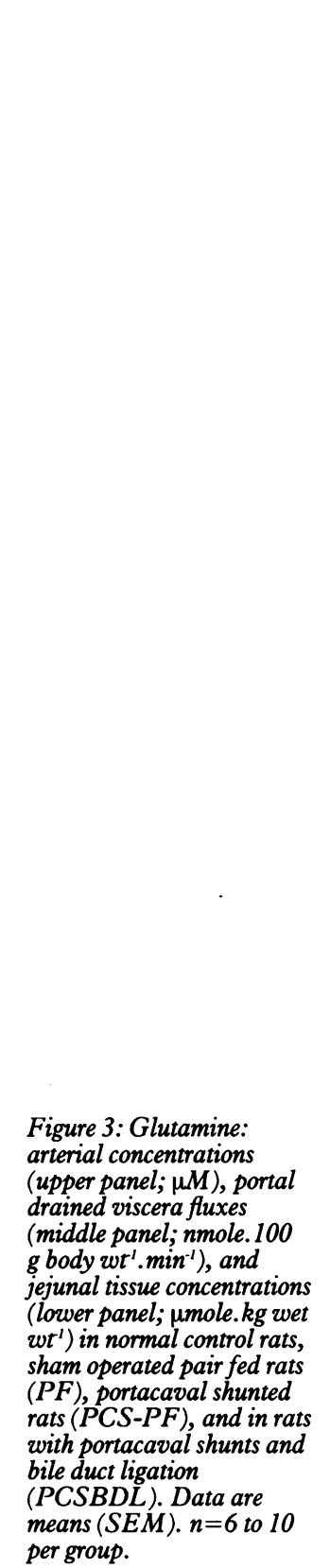

Figure 3: Glutamine: (upper panel; $\mu M)$, portal drained viscera fluxes (middle panel: nmole.100 g body $w t^{-1} \cdot$ min $\left.^{-1}\right)$, and jejunal tissue concentration wer panel; umole.kg wet erated pair fed rats PF), portacaval shunted with portacaval shunts and 位 means (SEM). $n=6$ to 10 per group.
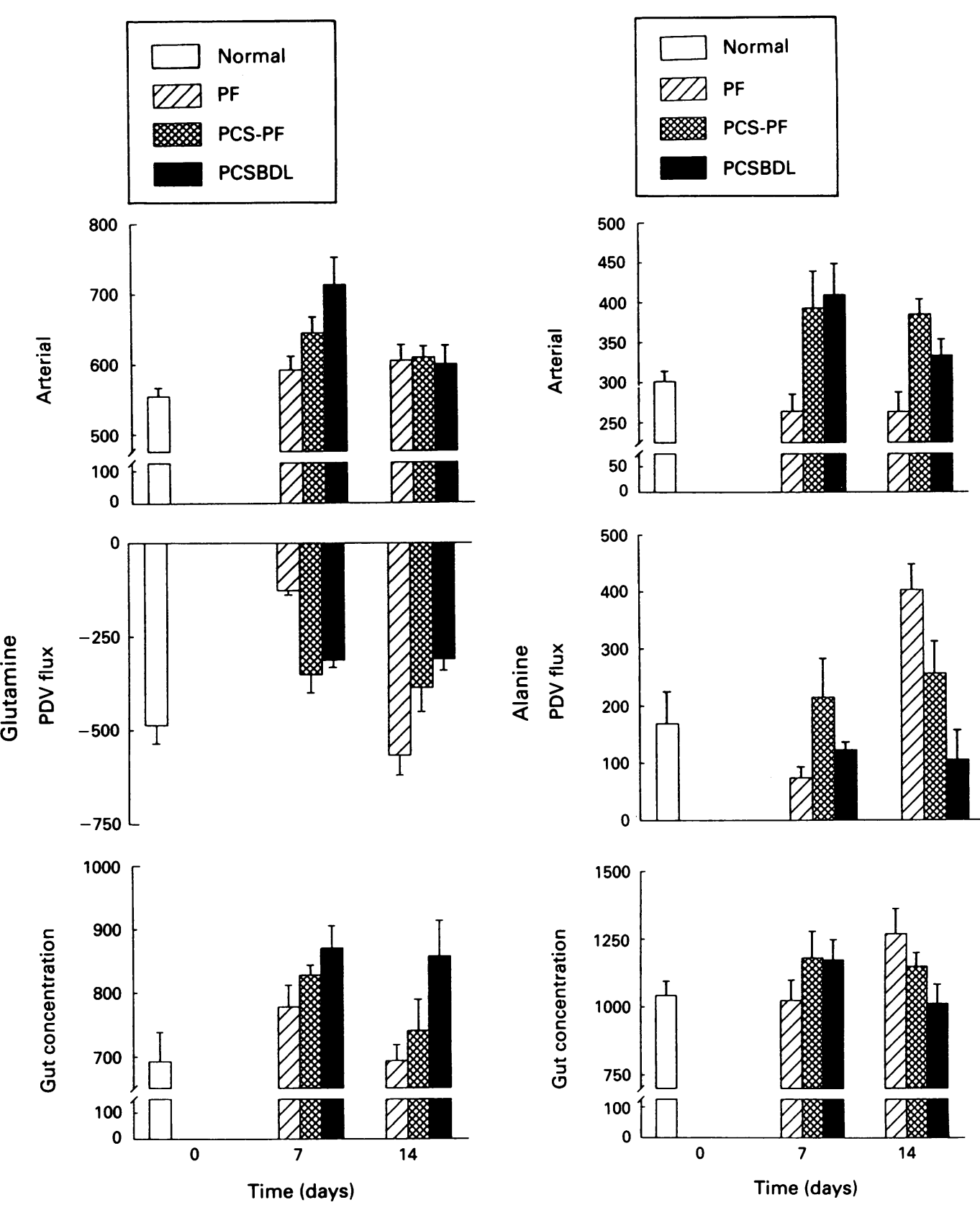

portal drained viscera was enhanced in both hyperammonaemic groups compared with sham operated animals, mainly caused by a reduced portal vein plasma flow in the PF group. No major differences were found at day 14 . Although arterial glutamine concentrations were always higher in the hyperammonaemic groups, glutamine uptake by portal drained viscera never exceeded that in normal controls. Simultaneously, jejunal glutamine concentrations were raised in PCSBDL compared with PF rats at both time points. The changes in glutamine and ammonia handling make it of special interest to look at some key metabolites intimately related to the intestinal breakdown of glutamine - namely, alanine, glutamate, and citrulline (Fig 3; Tables II-IV).

\section{ALANINE}

Arterial alanine concentrations were raised in both chronic liver insufficiency groups at both times. Alanine efflux from portal drained viscera
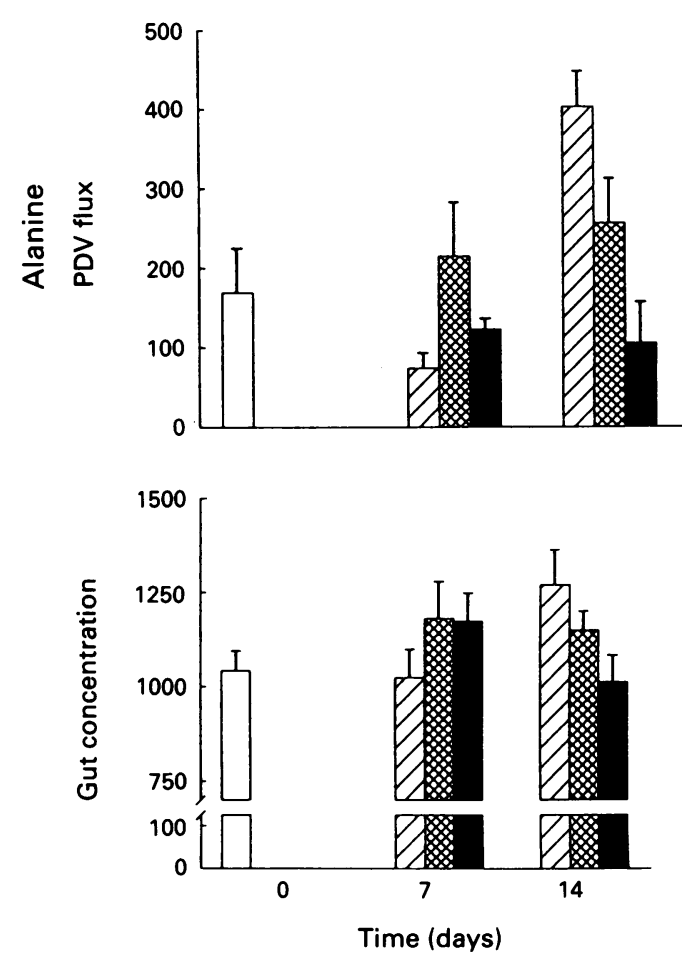

Figure 4: Alanine: arterial concentrations (upper panel; $\mu M$ ), portal drained viscera fluxes (middle panel; nmole. $100 \mathrm{~g}$ body $\mathrm{wt}^{l} \cdot \mathrm{min}^{-1}$ ), and jejunal tissue concentrations (lower panel; umole. $k g$ wet wt $t^{l}$ in normal control rats, sham operated pair fed rats $(P F)$, portacaval shunted rats

$(P C S-P F)$, and in rats with portacaval shunts and bile duct ligation $(P C S B D L)$. Data are means $(S E M) . n=6$ to 10 per group.

was decreased overall in the PCSBDL group compared with both PF and PCS-PF rats (ANOVA days 7 to 14). Also, at day 14 alanine release was lower in the PCS-PF group compared with PF rats. Despite these changes, no major differences in tissue alanine were found (Fig 4; Tables II-IV).

\section{GLUTAMATE}

At both time points arterial glutamate was diminished in PCSBDL rats compared with that in PCS-PF and PF rats. Only minor amounts of glutamine uptake could be accounted for by glutamate release, in agreement with published reports. ${ }^{728}$ Glutamate release by the portal drained viscera was slightly lower in the PCS-PF 

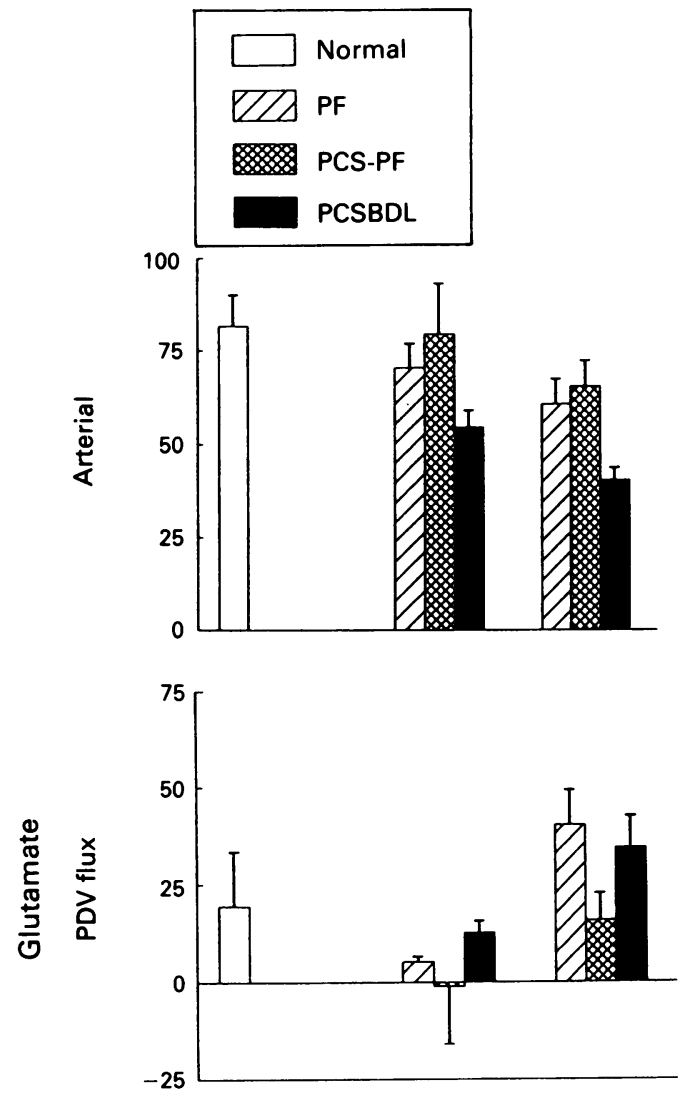

Figure 5: Glutamate: arterial concentrations (upper panel; $\mu M$ ) portal drained viscera fluxes (middle panel; nmole. $100 \mathrm{~g}$ body $w t^{l} \cdot$ min $\left.^{-1}\right)$, and jejunal tissue concentrations (lower panel: $\mu$ mole. $k g$ wet $\left.w t^{\prime}\right)$ in normal control rats, sham operated pair-fed rats $(P F)$, portacaval shunted rats $(P C S-P F)$, and in rats with portacaval shunts and bile duct ligation (PCSBDL). Data are means (SEM). $n=6$ to 10 group.

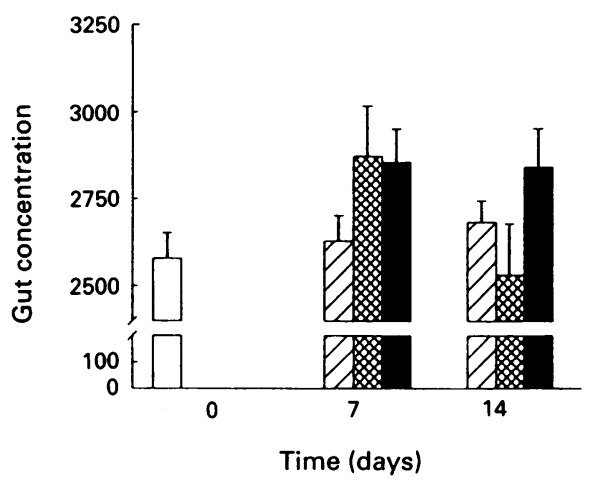

group compared with all other groups, but no further differences were found. Glutamate concentrations in jejunal tissue were increased in the PCSBDL compared with the PF group, despite decreased arterial glutamate concentrations (Fig 5; Tables II-IV).

\section{CITRULLINE}

Arterial citrulline concentrations were raised in the PCSBDL group compared with that in PCS$\mathrm{PF}$ and PF rats. Citrulline production by the gut did not show major differences between the groups, although tissue citrulline concentrations were raised in the PCSBDL group.

REMAINING AMINO ACIDS: MAIN FINDINGS

Arterial branched chain amino acid (BCAA) concentrations were decreased in both chronic liver insufficiency groups compared with the PF group at both time points. Although BCAA fluxes were not significantly different from zero in most groups, BCAA concentrations in jejunal tissue were decreased in PCSBDL rats compared with all other groups. Arterial taurine concentrations were raised in PCS-PF compared with PF rats and in the PCSBDL group compared with all other groups. Taurine release by the portal drained viscera in the PCS-PF and PF groups reversed to uptake in the PCSBDL group, although taurine concentrations in jejunal tissue were already raised (Tables II-IV).

\section{Discussion}

The present experiments were designed to study intestinal ammonia and amino acid metabolism during hyperammonaemia induced by chronic liver insufficiency. Specifically, we were interested in whether raised arterial glutamine concentrations during chronic liver insufficiency would lead to enhanced intestinal glutamine uptake and subsequent ammonia release, thereby aggravating the already existing portasystemic shunting induced hyperammonaemia. To minimise the influence of differences in nutritional state, rats were studied under conditions of well controlled food intake. Studies were performed one and two weeks after surgery, as we have previously shown that button portacaval shunted rats recover from several of the metabolic disturbances of portacaval shunting after three to four weeks, probably due to the development of hepatopetal shunts. ${ }^{23}$

In the current experiments, the similar food intake and body weight in PCSBDL, PCS-PF, and $P F$ rats suggests that differences between PCS-PF and PF rats are due to portacaval shunting. Similarly, differences between PCSBDL and PCS-PF rats are related to the aggravated hepatic parenchymal injury and cholestatic jaundice, induced by prolonged biliary obstruction. ${ }^{29} 32$

Arterial ammonia concentrations were raised equally in PCS-PF and PCSBDL rats, compared with both PF and normal control rats. This was found at day 14, when intestinal ammonia production was similar in normal, PF, PCS-PF, and PCSBDL rats, as well as at day 7 when ammonia liberation was decreased in all operated groups compared with normal rats. The intestinal ammonia release in normal unoperated control rats was in close aggreement with data previously reported by our group. ${ }^{19}$ From these data it seems that the (degree of) hyperammonaemia in both chronic liver insufficiency groups is mainly caused by the existence of a portasystemic shunt and not by enhanced intestinal ammonia production. Although the PCSBDL group undoubtedly has more severe parenchymal damage than the PCS-PF group, arterial ammonia concentrations were similar. This could easily by interpreted as evidence that the residual liver function is still able to detoxify total body ammoniagenesis in this PCSBDL model. In a steady state situation as in our experiments, however, arterial ammonia concentrations do not give information about the rate of whole body ammoniagenesis and detoxification, except that these antagonistic processes are of equal magnitude. Thus ammoniagenesis in other organs (for example, the kidney) may be reduced or alternatively, as we have found previously 
(unpublished results), urinary ammonia excretion may be enhanced in the PCSBDL group.

At day 7 ammonia production by portal drained viscera was less in PF than in PCS-PF rats. This deserves some specific comment. The decrease in ammonia production by portal drained viscera in the PF group was mainly caused by a decreased portal vein plasma flow, because portal veinarterial ammonia concentration differences (not shown) were similar in all operated groups. To exclude the possibility of an artificially decreased flow by coincidence or technical failure, we repeated portal plasma flow measurements in a similar series of five PF rats, treated and fed identically, and found the same value. Thus we must assume that the decreased plasma flow in the PF group at day 7 is a true finding for which we do not have an adequate explanation.

In PF as well as PCS-PF and PCSBDL rats, surgery and seven days of semistarvation resulted in an increase in arterial glutamine concentrations. No differences between the groups were found, however, on day 14, despite substantial differences in arterial ammonia concentrations. These findings suggest that the regulation of arterial glutamine concentrations is more related to nutritional factors or to surgical trauma than to hyperammonaemia or liver insufficiency themselves.

Although arterial glutamine concentrations were always higher in the PF, PCS-PF, and PCSBDL groups than in normal control rats, glutamine uptake by portal drained viscera in the PF, PCS-PF, and PCSBDL groups never exceeded that in normal control rats. The glutamine uptake in portal drained viscera in normal controls was similar to data recently reported by our group. ${ }^{19}$ Also, although the raised arterial glutamine concentrations at day 7 in PCSBDL rats compared with PF rats resulted in increased glutamine uptake by portal drained viscera, this was not accompanied by a significantly increased intestinal release of ammonia. Finally, the fractional glutamine extraction of about $30 \%$ in normal controls, closely resembling that reported by Windmueller and Spaeth, ${ }^{78}$ decreased in the hyperammonaemic groups. The hypothesis underlying this study was that hyperglutaminaemia during chronic liver insufficiency would enhance intestinal glutamine consumption and subsequent ammonia release, thus aggravating the already existing portasystemic shunting induced hyperammonaemia. From the present data we conclude that this hypothesis does not apply to these hyperammonaemia models in the rat.

There were several other interesting findings. Intestinal release of taurine in all other groups reversed to uptake in the PCSBDL group. This could indicate that in rats with the bile duct ligated, taurine is not excreted in the bile and therefore cannot be taken up from the luminal side, but instead is taken up from the blood. No data are available concerning the free taurine concentration of bile, ${ }^{33}$ but taurine can be assumed to be present in considerable amounts in bile as bile salt conjugates. ${ }^{34}$ It is likely that these bile salts can function as a source for intestinal taurine uptake. The fact that intestinal glycine release in PCSBDL rats was significantly decreased provides additional evidence that such a mechanism may be operative, because the part of bile salts not conjugated with taurine consists of glycine conjugates. ${ }^{34}$ The final metabolic fate for the taurine taken up remains to be clarified.

The finding that intestinal glutamine uptake was less in the hyperammonaemic and sham operated groups than in normal control rats makes it of special interest to consider the fluxes of the most important nitrogenous products (other than ammonia) of intestinal glutamine breakdown - namely, glutamate, alanine, and citrulline. $^{7283536}$ Alanine release from the intestines decreased at day 14 in both hyperammonaemic groups compared with sham operated rats, which seems to be compatible with the reduced intestinal glutamine uptake. Also intestinal release of citrulline did not change appreciably in hyperammonaemic rats. This could mean that other sources are also important precursors for citrulline release. It seems as if citrulline release is kept constant to provide precursors for renal arginine biosynthesis. ${ }^{28}$ Glutamate fluxes across portal drained viscera did not differ significantly from zero in several groups and could only account for minimal amounts of glutamine uptake. This is compatible with published data suggesting that glutamate, whether taken up from the luminal side or derived from mucosal glutamine breakdown, is completely utilised by the intestines. ${ }^{8}$

The changes in jejunal tissue concentrations are difficult to interpret. The increased tissue glutamine concentrations in both hyperammonaemic groups suggest that glutamine breakdown in the glutaminase reaction is diminished, which seems supported by the decreased glutamine uptake and fractional glutamine extraction. This does not seem compatible with the simultaneously raised concentrations of glutamate and ammonia, the products of the glutaminase reaction. Because intestinal glutamine synthetase activity is low, ${ }^{1428}$ probably the only plausible alternative explanation for increased jejunal glutamine concentrations is enhanced intestinal breakdown of protein. This should lead to enhanced intestinal release of essential amino acids, however, which was not found either. Thus presumably the changes reflect the end result of a new equilibrium, in which raised intestinal ammonia concentrations ${ }^{13}$ partially inhibit mucosal glutaminase activity. The glutaminase reaction, yielding energy for the gut,${ }^{28}$ can then only be driven at the expense of raised tissue glutamine concentrations, provided by uptake of blood derived glutamine. Also in the light of this, the decreased tissue BCAA concentrations in the PCSBDL group could be due to enhanced BCAA transamination, providing glutamate and $\alpha$ ketoglutarate for energy. Firm conclusions are, however, not justified based on the present data.

In the present experiments, portacaval anastomosis combined with common bile duct ligation was introduced as a model to study nitrogen metabolism during chronic liver insufficiency. Construction of a portacaval anastomosis alone induces, besides portasystemic shunting of gut derived blood, a relative and 
absolute reduction of liver mass. ${ }^{15-1737}$ Urea synthesis capacity is limited in portacaval shunted rats, probably related to the reduced liver mass. ${ }^{1516}$ To these effects of portacaval anastomosis alone, the effects of chronic bile duct ligation were added. Prolonged common bile duct ligation induces periportal fibrosis, portal hypertension, and portasystemic shunting $^{2931}$ as well as metabolic dysfunction of the liver. ${ }^{30}{ }^{31}$ Although the resulting jaundice is of a different aetiology from that commonly encountered in cirrhotic patients, it is also cholestatic and therefore introduces impaired cell mediated immunity and Kupffer cell dysfunction $^{30-32}$ in the model of portacaval shunting with biliary obstruction. Because portacaval shunted rats with biliary obstruction showed subtle signs pointing to more pronounced hepatic encephalopathy, we think that the portacaval shunt and biliary obstruction model could be useful in future studies on the pathophysiology of chronic liver insufficiency and the related hepatic encephalopathy.

In conclusion, these experiments show that under conditions of standardised food intake, ammonia generation by portal drained viscera remained unchanged in rats with chronic liver insufficiency despite alterations in arterial glutamine and intestinal glutamine uptake. This suggests that arterial ammonia concentrations in these rats are mainly determined by the existence of portasystemic shunting and not by arterial glutamine concentrations, intestinal glutamine uptake, or ammonia liberation. Finally, portacaval shunting combined with common bile duct ligation seems to be a useful model to study nitrogen metabolism during mild hyperammonaemia induced by chronic liver insufficiency in rats.

We thank Mr H M H van Eijk, Mrs M A H van der Heijden, and Mrs M A Janssen for laboratory determinations.

1 Record CO. Neurochemistry of hepatic encephalopathy. Gut 1991; 32: 1261-3.

2 Weber FL, Veach GL. The importance of the small intestine in gut ammonium production in the fasting dog. Gastroenterology 1979; 77 : 235-40.

3 Weber FL, Friedman DW, Fresard KM. Ammonia production from intraluminal amino acids in canine jejunum. Am $\mathcal{f}$ Physiol 1988; 254: G264-8.

4 Imler M, Schlienger J-L, Chabrier G, Comte F. Origine rénale de l'hyperammoniémie provoquée par un régime hyperprotidique chez le rat normal ou par un régime hyperprotidique chez le rat normal ou porteur d'

5 Imler M, Schlienger J-L, Chabrier G, Simon C. Arterial ammonia changes of renal origin induced in the rat by acid and alkaline diets. Res Exp Med 1986; 186: 353-63.

6 Imler M, Schlienger J-L. The effect of chronic uremia on portal and systemic ammonemia in normal and portalstrictured rats. F Lab Clin Med 1979; 94: 872-8.

7 Windmueller HG, Spaeth AE. Uptake and metabolism of plasma glutamine by the small intestine. F Biol Chem 1970; 249: 5070-9.

8 Windmueller HG, Spaeth AE. Intestinal metabolism of glutamine and glutamate from the lumen as compared to glutamine from blood. Arch Biochem Biophys 1975; 171: $662-72$
9 Zieve L. Pathogenesis of hepatic encephalopathy. Metab Brain Dis 1987; 2: 147-65.

10 Meijer AJ, Lamers WH, Chamuleau RAFM. Nitrogen metabolism and ornithine cycle function. Physiol Rev 1990; 70: $701-48$

11 Kaiser S, Gerok W, Haüssinger D. Ammonia and glutamine metabolism in human liver slices: new aspects on the pathogenesis of hyperammonaemia in chronic liver disease. Eur F Clin Invest 1988; 18: 535-42.

12 Gjedde A, Lockwood AH, Duffy TE, Plum F. Cerebral blood flow and metabolism in chronically hyperammonemic rats: Effect of an acute ammonia challenge. Ann Neurol 1978; 3: 325-30.

13 Newsholme EA, Leech AR. Biochemistry for the medical sciences. New York: John Wiley, 1983.

14 Lund $P$. A radiochemical assay for glutamine synthetase, and activity of the enzyme in rat tissues. Biochem $\mathcal{F} 1970$; 118: 35-9.

15 Brewer TG, Berry WR, Harmon JW, Walker SH, Dunn MA. Urea synthesis after protein feeding reflects hepatic mass in rats. Hepatology 1984; 4: 905-11.

16 Steele RD. Hyperammonemia and orotic aciduria in portacaval shunted rats. F Nutr 1984; 114: $210-6$

17 Benjamin IS, Engelbrecht GHC, Saunders SJ, van Hoorn Hickman R. Amino acid imbalance following portal diversion in the rat. The relevance of nutrition and of hepatic function. f Hepatol 1988; 7: 208-14.

18 Lockwood AH, McDonald JM, Reiman RE, Gelbard AS, Laughlin JS, Duffy TE, et al. The dynamics of ammonia metabolism in man. Effects of liver disease and hyperammonemia. F Clin Invest 1979; 63: 449-60.

19 Dejong CHC, Kampman MT, Deutz NEP, Soeters PB Altered glutamine metabolism in rat portal drained viscera and hindquarter during hyperammonemia. Gastroenterology 1992; 102: 936-48.

20 Dejong CHC, Kampman MT, Deutz NEP, Soeters PB. Cerebral cortex ammonia and glutamine metabolism during liver insufficiency-induced hyperammonemia in the rat. f Neurochem 1992; 59: 1071-9.

21 Dejong CHC, Deutz NEP, Soeters PB. Inter-organ nitrogen exchange during prolonged starvation in the rat. Fournal of Clinical Nutrition and Gastroenterology 1991; 6: 176-83.

22 Maddison JE, Dodd PR, Morrison M, Johnston GAR, Farrell GC. Plasma GABA, GABA-like activity and the brain GABA-benzodiazepine receptor complex in rats with chronic hepatic encephalopathy. Hepatology 1987; 7: 621-8.

23 de Boer JEG, Oostenbroek RJ, van Dongen JJ, Janssen MA, Soeters PB. Sequential metabolic characteristics following portacaval shunts in rats. Eur Surg Res 1986; 18: 96-106.

24 Deutz NEP, Dejong CHC, Athanasas G, Soeters PB. Partial enterectomy in the rat does not diminish muscle glutamine production. Metabolism 1992; 41: 1343-50.

25 Dejong CHC, Deutz NEP, Soeters PB. A simple new method for repeated in vivo cerebral cortex flux measurement in rats. Lab Anim Sci 1992; 42: 280-5.

26 van Eijk HMH, van der Heijden MAH, van Berlo CLH, Soeters PB. Fully automated liquid-chromatographic determination of amino acids. Clin Chem 1988; 34: 2510-3.

27 Ribeiro J, Nordlinger B, Ballet F, Cynober L, Coudray-Lucas $C$, Baudrimont $M$, et al. Intrasplenic hepatocellular transplantation corrects hepatic encephalopathy in portacaval shunted rats. Hepatology 1992; 15: 12-8.

28 Windmueller HG. Glutamine utilization by the small intestine. Adv Enzyme Regul 1982; 53: 210-37.

29 Kountouras J, Billing BH, Scheuer PJ, Prolonged bile duct obstruction: a new experimental model for cirrhosis in the rat. British fournal of Experimental Pathology 1984; 65 305-11

30 Greve JW, Gouma DJ, Soeters PB, Buurman WA. Suppression of cellular immunity in obstructive jaundice is caused by endotoxins. A study in germ-free rats. Gastroenterology 1990 98: 478-85.

31 Dunn CW, Horton JW, Megison SM, Vuitch MF. Contribution of portal systemic shunt to Kupffer cell dysfunction in obstructive jaundice. $\mathcal{F}$ Surg Res 1991; 50: 234-9.

32 Roughneen PT, Gouma DJ, Kulkarni AD, Fanslow WF, Rowlands BJ. Impaired specific cell-mediated immunity in experimental biliary obstruction and its reversibility by internal biliary drainage. $\mathcal{F}$ Surg Res $1986 ; 41$ : 113-25.

33 Fölsch UR, Wormsley KG. The amino acid composition of rat bile. Experientia 1977; 33: 1055-6.

34 Huxtable RJ. Physiological actions of taurine. Physiol Rev 1992; 72: 101-63.

35 Windmueller HG, Spaeth AE. Respiratory fuels and nitrogen metabolism in vivo in small intestine of fed rats. $\mathcal{F}$ Biol Chem 1980; 225: 107-12.

36 Windmueller HG, Spaeth AE. Identification of ketone bodies and glutamine as the major fuels in vivo for postabsorptive rats small intestine. $\mathcal{F}$ Biol Chem 1978; 253: 69-76.

37 Dunlop DS, Kaufman H, Zanchin G, Lajtha A. Protein synthesis rates in rats with portacaval shunts. 7 Neurochem synthesis rates in 